\title{
Study of antimicrobial activity of two common anti-cough formulations sold in Bangladesh
}

\author{
Tahmina Shammi* and Md. Ismam Khalid \\ Department of Microbiology, Stamford University Bangladesh, 51 Siddeswari Road, Dhaka 1217, Bangladesh
}

Received 18 March 2017/Accepted 28 April 2017

\begin{abstract}
Coughing is a physiological process of clarifying the mucosal obstruction through the airways is often be complicated by the invasion following infection by an array of microorganisms. A number of anticough formulations are available to combat coughing which is a non-antibiotic drug by nature; however, in some instances these drugs may exhibit anti-microbial trait in action probably due to the chemical properties of the contents. Present study aimed to determine such anti-microbial activity of two commonly used anti-cough mixtures which are locally formulated by the reputed pharmaceuticals in Bangladesh. The antibiotic susceptibility pattern of five laboratory strains of Escherichia coli, Klebsiella sp., Bacillus cereus, Pseudomonas aeruginosa and Staphylococcus aureus were tested by the agar well diffusion method against these two oral liquid samples under investigation used as anti-cough drugs. Sample 1 was found to be highly effective against all of the five test organisms whereas sample 2 was found to be effective against four of the tested organisms. Interestingly, even the lowest amount (50 $\mu \mathrm{l})$ of both drugs were able to mount inhibitory action against at least two test organisms, the highest amount of both drugs have been found to pose more antimicrobial action than their positive control Gentamycin $10 \mathrm{mg}$.
\end{abstract}

Key words: Drugs; Oral liquids; Coughing; Anti-microbial activity; Microorganisms

Cough is a suddenly occured repetitive reflex with characteristic sound that expulse air from the lungs to clear obstructions like -secretions, irritants, foreign bodies and microbes from the respiratory tract $(1,2)$. It is one of the most common complaints persuading patient visits to healthcare professionals and the second most common reason for a general medical diagnosis $(2,3)$. Cough is not a disease, instead it is the symptom of disease that occurs in respiratory tract (4) which can indicate serious illness if occurs too frequently. Most of the time, a respiratory tract infection by bacteria or virus cause irregular coughing (2) but it can also be triggered by choking, air pollution, smoking (1) and other medical conditions. As a common household disease many patients take prescribed or nonprescribed medicaments to treat coughing $(5,6)$.

Antitussive or cough suppressant and expectorant are the two basic short acting syrups for cough management. Suppressants like dextromethorphan, temporarily reduce coughing to normal level when its intensity is excessive $(7,8)$ and are generally considered as safe at recommended doses. Expectorant attempts to dampen excessive mucus production by liquefaction which improves the removal of secretions by ciliary

*Corresponding Author: Mailing address. Tahmina Shammi, Senior Lecturer Department of Microbiology, Stamford University Bangladesh, 51 Siddeswari Road, Dhaka 1217, Bangladesh, Bangladesh; E-mail: tahminashammi@yahoo.com. transport and/or by coughing (8-10).

In Bangladesh, Pharmaceutical manufacturers use Dextromethorphan hydrobromide, Pseudoephedrine hydrochloride, Triprolidine hydrochloride, Bromohexin hydrochloride etc. according to the guideline of USP and BP in both adult and children's cough mixtures. Often found in liquid formulation, these cough medicines sometimes contain antibacterial activity which is not commonly indicated in the remedy. Again, a common problem with liquid formulation is difficulty of precise measurement. Therefore, taking low or excessive dose than that of recommendation can result in drug resistance among the microorganisms of respiratory tracts and other body parts. Study of Antimicrobial activity of common cough mixtures is inadequate or has not been done yet. Hence, this study will examine the antimicrobial effect of antitussive and expectorant syrup commonly available and used in Bangladesh.

\section{MATERIALS AND METHODS}

Study site, sample collection and sample processing. Samples were randomly collected from drug store during August, 2016, according to the standard sampling method suggested by American Public Health Association (11). During collection both drug satisfied the manufacturing and expiry dates and storage criteria.

Determination of antimicrobial activity by agar well diffusion method. To observe in vitro antimicrobial activity, a standard procedure of agar well diffusion method was performed $(12,13)$. Agar well diffusion assay was observed against five common opportunistic pathogen found in respiratory tract. Escherichia coli, Klebsiella sp., Staphylococcus aureus, Pseudomonas aeruginosa and Bacillus cereus were the organisms tested in this study. Broth cultures of these organisms in Muller-Hinton Broth (MHB) were adjusted to the turbidity of Macfarland 
standard of 0.5 at first. Then with sterilized cotton swab, bacterial suspension was evenly spread on Muller-Hinton agar for confluent growth of each organism. With sterile cork-borer, four well of different size were made on agar plate to assay antimicrobial action. According to the size of the well different amount of drug $50 \mu \mathrm{l}, 150 \mu \mathrm{l}, 200 \mu \mathrm{l}$ and finally $500 \mu \mathrm{l}$ was added in the wells. For both positive and negative controls, disk of gentamicin $10 \mu \mathrm{g}$ and sterile MHB were used respectively. After overnight incubation at $37{ }^{\circ} \mathrm{C}$, presence of clear zone was indicative of the active compound in the tested samples against the five pathogens $(14,15)$

\section{RESULTS AND DISCUSSIONS}

Antimicrobial activities of non-antibiotic compounds have been demonstrated in several studies $(2,16,17)$. In another study in Nigeria antimicrobial activity of cough syrups was observed as well (2). But no data was found on similar activity on locally produced cough mixtures, although these over the counter drugs are very commonly used. Our current study was aimed to investigate the antimicrobial effect of locally produced oral cough syrups. Sample 1; being adult's cough suppressant, contains Dextromethorphan hydrobromide (DXM) BP $10 \mathrm{mg}$, Pseudoephedrine hydrochloride (PPH) BP $30 \mathrm{mg}$ and Triprolidine hydrochloride (TRL) BP $1.25 \mathrm{mg}$ in $5 \mathrm{ml}$ of mixture. And sample 2, children's expectorant contains $4 \mathrm{mg}$ of Bromhexin hydrochloride $(\mathrm{BXH})$ in $5 \mathrm{ml}$ formulation.

Pharmaceutical form rather than pure form of these two formulations were analyzed against five common pathogens. Both of the medicine showed significant amount of inhibitory effect as sample 1 was found inhibitory against all of the five test organisms and sample 2, inhibited growth of all organisms except Pseudomonas aeruginosa. When compared with the results of inhibition with the positive control Gentamycin $10 \mathrm{mg}$, inhibiting activity was greater with the test drugs. Result of antimicrobial activity by agar well diffusion is included in table 1 .

Against E.coli both sample 1 and sample 2 showed effective killing and diameter of clear zone was proportional with increased amount of drug concentration. Sample 1 mounted clear zone with diameter ranging from 18 to $26 \mathrm{~mm}$ with 50 to $500 \mu \mathrm{l}$, whereas, sample 2 produced clear zone with diameter ranging with 18 to 30 $\mathrm{mm}$ with similar amount of cough mixtures. Gentamycin $10 \mathrm{mg}$ showed a much smaller clear zone and the diameter was found only $12 \mathrm{~mm}$.

For Klebsiella spp. $50 \mu \mathrm{l}$ of both sample drugs failed to clear bacterial growth. Sample 1 found effective at $200 \mu \mathrm{l}$. Diameter of clear zone was $13 \mathrm{~mm}$ and $26 \mathrm{~mm}$ for $200 \mu \mathrm{l}$ and $500 \mu \mathrm{l}$ respectively. Sample 2 could mount killing effect at $150 \mu \mathrm{l}$ compared to $200 \mu \mathrm{l}$ of sample 1 and diameter of inhibition area ranged from 15 to $21 \mathrm{~mm}$. Again Gentamycin was much less effective, producing only $10 \mathrm{~mm}$ diameter of clear zone.

Only one pathogen Pseudomonas aeruginosa remained unaffected or resistant against sample 2, expectorant syrup. No inhibition of growth was observed even with the highest concentrations of this drug. But for sample 1, growth inhibition showed a similar pattern that with E.coli resulting in clear zone with diameter $11 \mathrm{~mm}$ with both 50 and $150 \mu \mathrm{l} .12 \mathrm{~mm}$ and $25 \mathrm{~mm}$ were found with $200 \mu \mathrm{l}$ and $500 \mu \mathrm{l}$ respectively. For Gentamycin clear zone exhibited a diameter of $20 \mathrm{~mm}$.

Both the sample drugs were found to have antimicrobial activity against gram positive bacteria. $50 \mu \mathrm{l}$ of sample 2 could not inhibit the growth of $B$. cereus and $S$. aureus. Interestingly, 150 and $200 \mu \mathrm{l}$ were equally inhibitory as diameters of clear zones were equal, $11 \mathrm{~mm}$ for B. cereus and $16 \mathrm{~mm}$ for $S$. aureus. $25 \mathrm{~mm}$ and $30 \mathrm{~mm}$ diameter were found for sample 1 against $B$. cereus and $S$. aureus

TABLE 1. Zone of inhition by agar well diffusion (diameter in $\mathrm{mm}$ ) aginst different concentration of cough mixtures

\begin{tabular}{|c|c|c|c|c|c|c|c|c|c|}
\hline \multirow[b]{3}{*}{ Organism } & \multicolumn{8}{|c|}{ Zone of inhition by agar well diffusion (diameter in $\mathrm{mm}$ ) } & \multirow{3}{*}{$\begin{array}{c}\text { Gentamycin } \\
\text { 10mg } \\
\text { (positive } \\
\text { control) }\end{array}$} \\
\hline & \multicolumn{4}{|c|}{ Sample 1} & \multicolumn{4}{|c|}{ Sample 2} & \\
\hline & $\begin{array}{c}50 \mu \mathrm{l} \\
(.41 \mathrm{mg})\end{array}$ & $\begin{array}{c}150 \mu \mathrm{l} \\
(.82 \mathrm{mg})\end{array}$ & $\begin{array}{c}200 \mu \mathrm{l} \\
(1.23 \mathrm{mg}\end{array}$ & $\begin{array}{l}500 \mu \mathrm{l} \\
(4.1 \mathrm{mg})\end{array}$ & $\begin{array}{c}50 \mu \mathrm{l} \\
(.04 \mathrm{mg})\end{array}$ & $\begin{array}{l}150 \mu \mathrm{l} \\
(.08 \mathrm{mg})\end{array}$ & $\begin{array}{l}200 \mu \mathrm{l} \\
(.12 \mathrm{mg})\end{array}$ & $\begin{array}{l}500 \mu \mathrm{l} \\
(.4 \mathrm{mg})\end{array}$ & \\
\hline Escherichia coli & 18 & 18 & 20 & 26 & 18 & 20 & 22 & 30 & 12 \\
\hline Klebsiella spp. & 0 & 0 & 13 & 20 & 0 & 15 & 20 & 21 & 10 \\
\hline $\begin{array}{c}\text { Pseudomonas } \\
\text { aeruginosa }\end{array}$ & 11 & 11 & 12 & 25 & 0 & 0 & 0 & 0 & 20 \\
\hline Bacillus cereus & 0 & 11 & 11 & 25 & 7 & 12 & 16 & 23 & 15 \\
\hline Staphylococcus aureus & 0 & 16 & 16 & 30 & 0 & 0 & 10 & 20 & 10 \\
\hline
\end{tabular}


respectively, showing sample 1 more effective against S. aureus.

Sample 2, children's expectorant mixture was found inhibitory with increased concentrations. Growth of $B$. cereus was inhibited progressively. $7 \mathrm{~mm}, 12 \mathrm{~mm}, 16$ $\mathrm{mm}$ and $23 \mathrm{~mm}$ respectively with 50, 150, 200 and 500 $\mu 1$. For $S$. aureus, inhibitory activity was lesser than that found against $B$. cereus. 10 and $20 \mathrm{~mm}$ against $200 \mu \mathrm{l}$ and $500 \mu$ l. Interestingly Gentamycin was found less inhibitory against both these organisms when compared with sample 1 and sample 2 . Clear zone was found with diameter of $15 \mathrm{~mm}$ and $10 \mathrm{~mm}$ against these two pathogens.

A comparison between the two test samples shows $500 \mu \mathrm{l}$ of sample 1 produced larger zone of inhibition than that of $500 \mu \mathrm{l}$ of sample 2. Average diameter of inhibition zone was $25.5 \mathrm{~mm}$ for sample 1 compared to $18.8 \mathrm{~mm}$ for sample 2. Gentamycin produced an average of $13.4 \mathrm{~mm}$ diameter against five pathogenic organisms.

A total of $18 \mathrm{~mm}$ diameter of clear zone against $E$. coli and other organisms was also found in previous studies which are supportive to present data $(2,18)$. Active compounds used in the two studied cough mixtures are mostly non antibiotic with antitussive, decongestant and sometimes with antioxidant activity. But Triprolidine hydrochloride in sample 1 is a known antihistamin compound and antimicrobial activity of some antihistamin compounds have been reported in an experiment (18).

\section{CONCLUSION}

Present study is an indication of antibacterial activity of two commonly used cough mixtures, which were previously known as non-antibiotic. This study shows the cough mixtures were inhibitory to bacterial growth in very little amounts than broad spectrum Gentamycin $10 \mathrm{mg}$. Further investigation should be conducted to find the underlying reason of this high antimicrobial activity.

\section{ACKNOWLEDGEMENT}

Special thanks to Microbiology Laboratory, Stamford University Bangladesh for laboratory facilities, technical assistance and financial aid.

\section{REFERENCES}

1. Chung KF, Pavord ID. 2008. Prevalence, pathogenesis, and causes of chronic cough. Lancet. 371 (9621):1364-74. doi:10.1016/S01406736(08)60595-4.PMID 18424325.

2. Olajuyigbe OO, Ogra EA, Afolayan AJ. 2012. Antibacterial activity of some of the commonly sold cough mixtures in South Western Nigeria. Afr. J. Microbiol. Res. 6 (8): 1855-1859.

3. Schappert SM. 1993. National ambulatory medical care: 1991. Vital and Health Statistics No. 230. US Department of Health and Human Services.

4. Molyneux ID, Morice AH. 2011. Airway reflux, cough and respiratory disease. Therapeutic Advances in Chronic Disease. 2 (4):237-248.

5. Irwin RS, Corrao WM, Pratter MR. 1981. Chronic persistent cough in the adult: the spectrum and frequency of causes and successful outcome of specific therapy. Am. Rev. Resp. Dis. 123: 413-17.

6. Irwin RS, Curley FJ, French CL. 1990. Chronic cough: the spectrum and frequency of causes, key components of the diagnostic evaluation and outcomes of specific therapy. Am. Rev. Resp. Dis. 141: 640-647.

7. Bolser DC. 2006. Cough suppressant and pharmacologic protussive therapy: ACCP evidence-based clinical practice guidelines. Chest. 129: 238S-249S.

8. Dicpinigaitis PV, Colice GL, Goolsby MJ, Rogg GI, Spector SL, Winther B. 2009. Acute cough: a diagnostic and therapeutic challenge. Cough. 5: 11.

9. Smith SM, Schroeder K, Fahey T. 2008. Over-the-counter medications for acute cough in children and adults in ambulatory settings. Cochrane Database Syst Rev. CD001831.

10. Ziment I. 1976. What to expect from expectorants. JAMA. 236: 193-194.

11. American Public Health Association. 1998. Standard Methods for the Examination of Water and Wastewater. American Public Health Association, Washington, D.C

12. Ahmed T, Urmi NJ, Munna MS, Das KK, Acharjee M, Rahman MM, et al. 2014. Assessment of microbiological proliferation and in vitro demonstration of the antimicrobial activity of the commonly available salad vegetables within Dhaka metropolis, Bangladesh. Am. J. Agri. Forestr. 2014;2 (3): 55-60.

13. Hussain A, Wahab S, Zarin I, Hussain MDS. 2010. Antibacterial activity of the leaves of Cocciniaindica (W. and A) of India. Adv Biol Res. 4 (5): 241248 .

14. Sharmin M, Nur IT, Acharjee M, Munshe SK, Noor R. 2014. Microbiological profiling and the demonstration of in vitro antibacterial traits of the major oral herbal medicines used in Dhaka Metropolis. SpringerPlus. 3: 739.

15. Ferraro MJ, Craig WA, Dudley MN. 2001. Performance standards for antimicrobial susceptibility testing, Ed 11, NCCLS, Pensylvania, USA, 2001.

16. Mazumder R, Chaudhuri SR, Mazumder A. 2002. Antimicrobia potentiality of a phenothiazine group of antipsychotic drugprochlorperazine. Ind. J. Exp. Biol. 40: 828-30.

17. Sarkar A, Kumar KA, Dutta NK, Chakraborty P, Dastidar SG. 2003 Evaluation of in vitro and in vivo antibacterial activity of dobutamine hydrochloride. Ind. J. Med. Microbiol. 21: 172-8.

18. Kristiansen JE, Hendricks O, Delvin T, Butterworth TS, Aagaard L, Christensen JB, et al. 2007. Reversal of resistance in microorganisms by help of non-antibiotics. J. Antimicrob. Chemother. 59: 1271-9. 